\title{
The Utility of the helicobacter pylori stool antigen test in managing dyspepsia: an experience from a low resource setting
}

\author{
Innocent Lule Segamwenge, Magid Kagimu, Ponsiano Ocama, Kenneth Opio
}

Makerere University College of Health sciences, School of Medicine, Department of Internal Medicine, Gastroenterology Division

\begin{abstract}
Background: Dyspepsia is defined as a chronic or recurrent pain or discomfort centered in the upper abdomen. Endoscopy is the best strategy for confirming the cause of dyspepsia. Non- invasive strategies would be more appropriate in low resource countries where endoscopy is not readily available. However, there is concern that these strategies may miss serious disease like gastric cancer. One test that needs to be assessed in this regard is the Helicobacter pylori stool antigen test (HPSAT).

Objective: To determine the validity of the stool antigen test in predicting H. pylori associated disease among patients with dyspepsia.

Methods: In this prospective study patients with dyspepsia attending Mulago Hospital were recruited consecutively. Helicobacter pylori was determined using the Rapid Strip HpSA $\mathbb{~}$, endoscopy and gastric mucosal biopsy were done.

Results: 167 patients with dyspepsia were recruited into the study. There were ninety six (57.5\%) females and seventy one $(42.5 \%)$ males with an average age of $48.1( \pm 18.1)$ years. Patients presenting with dyspepsia in Mulago hospital were more likely to come from the Central $60(36 \%)$ and western tribes $55(33 \%)$. The commonest endoscopic finding was oesophagitis 25 (15\%). Peptic ulcer disease was found in $32(19.2 \%)$ and $54(32.3 \%)$ had normal endoscopy findings. H pylori was found in 33.5\% and 32.5\% using the HPSAT and histology respectively. The validity of the HPSAT in predicting H.pylori associated diseases was generally low with an overall sensitivity of $55.8 \%$, and specificity of $74.2 \%$. However, the validity was higher in predicting the diagnosis of peptic ulcer disease with a sensitivity $59.4 \%$ and specificity $72.6 \%$.

Conclusion and recommendations: The HPSAT may be used in the test and treat strategy for young patients with dyspepsia without alarm signs and symptoms in low resource settings. However, because of its low validity in predicting H.pylori associated disease, it is important to follow up patients so that if symptoms persist or recur endoscopy is performed
\end{abstract}

Keywords: helicobacter pylori, stool antigen, dyspepsia, low resource setting

DOI: http://dx.doi.org/10.4314/ahs.v14i4.9

\section{Introduction}

Dyspepsia is defined as a chronic or recurrent pain or discomfort centered in the upper abdomen ${ }^{1}$. Helicobacter pylori associated diseases such as peptic ulcer disease, gastritis and gastric cancer commonly present as dyspepsia. In the evaluation of dyspepsia, clinical signs and symptoms have a limited role because they do not reliably predict underlying pathology and endoscopy findings ${ }^{2}$. Symptom assessment by medical workers is therefore not sufficient in the evaluation of the cause of dyspepsia.

\section{Corresponding author:}

Innocent Lule Segamwenge

Makerere University College of Health sciences,

School of Medicine, Department of Internal

Medicine, Gastroenterology Division

Email: sslule@yahoo.com
Endoscopy is the best strategy for confirming the cause of dyspepsia. However, it is an expensive procedure and is not readily available in low resource countries. One of the main reasons for performing endoscopy in patients with dyspepsia is to detect underlying H.pylori associated diseases like peptic ulcer.

Non-invasive testing of $\mathrm{H}$. pylori using the urea breath test has been shown to be a useful surrogate marker of peptic ulcer disease in patients with dyspepsia in a study conducted in the United Kingdom ${ }^{3}$.

The Helicobacter pylori stool antigen (HPSAT) test has been shown to be another accurate non-invasive test for the initial diagnosis of H.pylori infection ${ }^{4}$. However, there is no data on its utility in managing dyspepsia in low resource countries. It is in light of the above that we conducted this study. 
Methods

On the day endoscopy was scheduled, the procedure This was a descriptive cross sectional study con- was done according to the standard protocol. At enducted among patients with dyspepsia presenting doscopy a description of the findings was done and to the gastroenterology division of Mulago hospital three gastric mucosal biopsies for histology were taken between October 2009 to April 2010. All patients off.

with dyspepsia 12 years and above who had provided

consent to participate in the study were consecutively enrolled into the study. The patients had to have been off proton pump inhibitor therapy and antibiotics for atleast 2 weeks. We excluded patients with dyspepsia attributable to non- steroidal ant-inflammatory drugs, dysphagia and those with epigastric pain due to pancreatic or hepatic disease.

A physical examination was conducted and a question- One hundred and ninety seven (197) patients who atnaire was administered to obtain social demographics, tended the Gastroenterology division of Mulago hospiseverity of dyspepsia symptoms, alarm signs and symp- tal were screened for eligibility. One hundred and sixty toms. The study participants were asked to provide a seven (167) patients with dyspepsia were recruited into stool sample for H.pylori testing on the morning of the study (Figure 1). One hundred and sixty patients endoscopy was performed. The stool was tested imme- had gastric mucosal biopsy done.

diately using the Rapid Strip HpSA ${ }^{\circledR}$ from Meridian

bioscience Europe

\section{Figure 1: Patient flow chart}

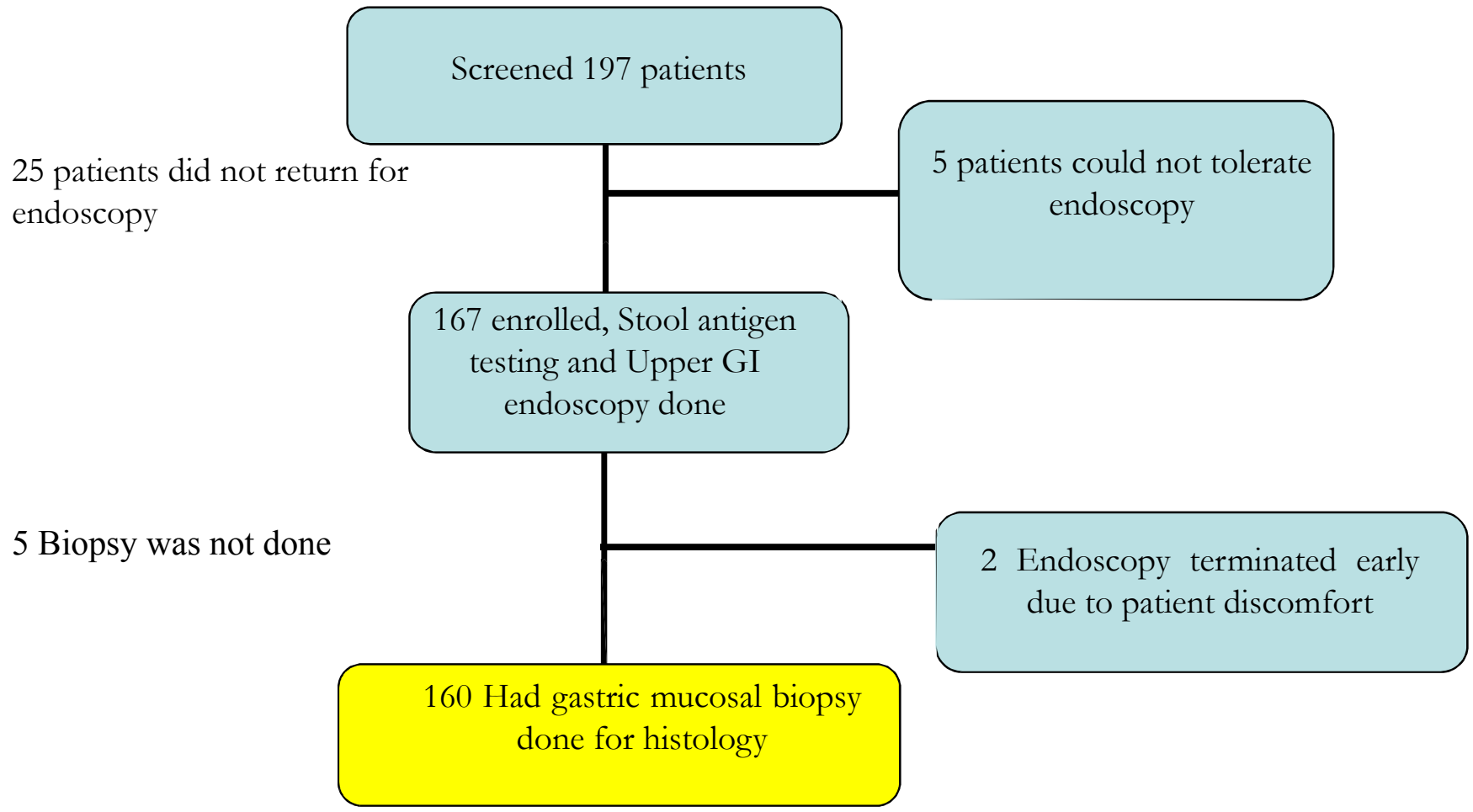

There were ninety six $(57.5 \%)$ females and seventy one $48.1( \pm 18.1)$ years with a range of 13 to 84 years $(42.5 \%)$ males. The average age of the participants was (Table1)
Table 1: socio-demographic characteristics Variable
Percentage

Number $(n=167)$

Age
(years)

$>45$
46.7

$<45$
53.3

Female

Male
42.5

Regio

$\mathrm{Reg}$

Central

Western

Northern

Eastern

Non-Ugandan

The commonest H.pylori associated endoscopic di- Oesophagitis was the commonest non-H.pylori associagnoses in order of frequency were gastric ulcer 18 ated endoscopic diagnosis, found in $25(15 \%)$. Normal $(10.8 \%)$, duodenal ulcer $17(10.2 \%)$, cancer of endoscopy was found in a significant proportion of pathe stomach 12 (7.2\%), and duodenitis 9 (5.4\%). tients 54 (32.3\%) (Table 2 ).

\section{Table 2: Endoscopic and histologic diagnoses among patients with}

\section{dyspepsia}

Endoscopic/histologic diagnosis

Percentage

Number(N=167)

Normal

Gastric ulcer

54

Duodenal ulcer

Cancer of the stomach

10.2

Oesophagitis

Candidiasis

9

Oesophageal varices

3.6

Others 
The majority of the patients with cancer of the stom- diseases, the highest prevalence of H.pylori was found ach $9(75 \%)$ were above 45 years and had alarm features among patients with duodenal ulcer using the HPSAT. (Table 3). It was found in $10(58.8 \%)$ of these patients duodenal ulcers. It was followed by gastric ulcer $55.6 \%$ and gasThe prevalence of Helicobacter pylori was $33.5 \%$ and tric cancer $50 \%$. Among the patients with a normal $32.5 \%$ as determined by the HPSAT and histology re- endoscopic diagnosis, the prevalence of H.pylori using spectively. Among patients with H.pylori associated the HPSAT was low at $24.1 \%$ (table 4).

\section{Table 3: Characteristics of patients with Cancer of the Stomach}

Variable

Number $(\mathrm{n}=12)$

Percentage

Age

Below 45 years

Above 45 years

Alarm features

The overall sensitivity of the stool antigen test in pre- with a sensitivity and specificity of $58.8 \%$ and $69.3 \%$ dicting H.pylori associated disease among patients with respectively followed by gastric ulcer with sensitivity of dyspepsia is $55.8 \%$, specificity is $74.2 \%$ while the posi- $55.6 \%$ and sensitivity of $69.1 \%$ (table 4 ). The test overtive and negative predictive values are $42.9 \%$ and $82.9 \%$ all showed a high negative predictive value for all the respectively. It was higher in predicting duodenal ulcer H.pylori associated diseases.

\section{Table4: Endo scopic diagnoses and prevalence Helicobacter pylori}

\section{Helicobacter pylori HPSAT}

\section{Positive}

Overall H.pylori prevalence

$56(33.5 \%)$

Negative

$111(66.5 \%)$

Endoscopic diagnosis

Gastric ulcer

Gastric cancer

Duodenal ulcer

Duodenitis
$8(44.4 \%)$

$6(50 \%)$

$3(33.3 \%)$

$6(66.7 \%)$
Other endoscopic findings include: Gastric Polyps $1(0.6 \%)$, gastric Kaposis sarcoma 1(0.6\%), gastric

Mass $1(0.6 \%)$, Barrett's oesophagus $1(0.6 \%)$, dilated

oesophagus $2(1.2 \%)$, oesophageal ulcers $3(1.8 \%)$, Ca outlet obstruction $5(3 \%)$, portal hypertensive gastropa- oesophagus $1(0.6 \%)$, hiatus hernia $3(1.8 \%)$. Table 5 thy1 $(0.6 \%)$, duodenal mass $2(1.2 \%)$, extrinsic duodenal

Table 5: Utility of the HPSAT in predicting Helicobacter pylori associated diseases among patients with dyspepsia

\begin{tabular}{l|cccc}
\multicolumn{1}{c}{ Validity } & Gastric ulcer & Duodenal ulcer & Gastric & H.pylori \\
Sensitivity (\%) & 55.6 & 55.8 & 50 & 55.8 \\
$\begin{array}{c}\text { Specificity (\%) } \\
\begin{array}{c}\text { Positive predictive } \\
\text { value (\%) }\end{array}\end{array}$ & 69.1 & 69.3 & 67.7 & 74.2 \\
$\begin{array}{c}\text { Negative predictive } \\
\text { value (\%) }\end{array}$ & 92.8 & 18 & 10.7 & 42.9 \\
& & 93.7 & 94.6 & 82.9
\end{tabular}

\section{Discussion}

In this study, oesophagitis $25(15 \%)$ was the commonest endoscopic diagnosis. Gastric ulcer was found in18 $(10.8 \%)$ and duodenal ulcer in $17(10.2 \%)$. These findings are similar to earlier studies in Mulago hospital ${ }^{5}$. Other studies from Africa have reported higher rates of duodenal ulcer ${ }^{6}$. In both these studies the prevalence of $\mathrm{H}$. pylori was above $70 \%$. It is possible that the high prevalence of H.pylori was responsible for the observed differences in the frequency of peptic ulcer disease. Gastric cancer was found in $12(7.2 \%)$ which is similar to findings from other African studies 578 . A large proportion of the patients with gastric cancer were from the western tribes $6(50 \%)$. In addition the majority of these patients with cancer of the stomach were over 45 years of age and had alarm features (Table 3). Ibingira had similar results in 2001 where he found $49 \%$ of the patients were from south western Uganda The mean age of his patients was 53.8 years for females and 56.1 for males?.

The overall prevalence of Helicobacter pylori among patients with dyspepsia at Mulago hospital was 33.5\% as determined by the H.pylori stool antigen test while it was $32.5 \%$ as determined by histology. It is possible therefore that the prevalence of active H.pylori in fection is much lower than the sero-prevalence. In our study patients were required to have been off proton pump inhibitor and antibiotics for atleast two weeks, However, most of our patients $146(73 \%)$ reported symptoms lasting over 4 weeks and during that period $63(38.9 \%)$ had been prescribed atleast one of the antibiotics used for H.pylori treatment. It is possible that some of these patients could have eradicated the organism before testing had been done, leading to a lowe prevalence rate. In Ghana and Nigeria prevalence rates of $75.4 \%, 73 \%$ and $81 \%$, have been reported using histology and CLO urease tests ${ }^{71011}$. It is possible that the prevalence of active infection has declined in Uganda while that in Ghana and Nigeria has remained constant. Other studies may therefore be needed to determine the prevalence of active H.pylori infection in Uganda and if there have been any changes in the pattern over he years. In developed countries the prevalence of

The HPSAT had a higher validity in predicting diagnosis of peptic ulcer disease with a sensitivity of $59.4 \%$ and specificity of $72.6 \%$ and in predicting the diagnosis of cancer of the stomach with a sensitivity of $50 \%$ and specificity of $67.7 \%$. With this overall low sensitivity the HPSAT may still be used in the test and treat strategy especially in low resource settings, among young patients less than 45 years of age with no alarm symptoms. In this age group even if the test missed to predict some cases of H.pylori associated diseases, these are relatively few and most of them are benign. In any case, using this strategy, the H.pylori negative patients would be treated with a PPI(proton pump inhibitor) which may result in improvement in the benign H.pylori has been noticed to be decreasing ${ }^{12}$. 
H.pylori associated diseases. However, it is important to follow up patients when this strategy is used, so that if symptoms persist, endoscopy is done to confirm the diagnosis of any H.pylori associated disease that may have been missed by a negative HPSAT.

\section{Conclusions}

The helicobacter pylori stool antigen test may have a role in the non-invasive management of dyspepsia in low resource setting. In our study most of the patients with cancer of the stomach were above 45 years and all had alarm features.

We recommend the use of the HPSAT in the non-invasive management of dyspepsia in low resource settings only for young people less than 45 years old without alarm signs and symptoms. However, because of its low validity in predicting H.pylori associated disease, it is important to follow up patients so that if symptoms persist or recur endoscopy is performed.

\section{Abbreviations}

HPSAT, Helicobacter pylori stool antigen test; H.pylori, Helicobacter Pylori; PPI, Proton pump inhibitor; CLO test, Campylobacter-like organism test

\section{Competing Interests}

The authors declare that they have no competing interest

\section{Acknowledgements}

We are grateful to the staff of the endoscopy Unit Mulago Hospital who participated in the data collection and Mr Luswata Charles for his assistance in data analysis.

\section{References}

1. Talley NJ, Vakil N. Guidelines for the Management of Dyspepsia. Am J Gastroenterol 2005;100(10):2324-37.

2. Thomson AB, Barkun AN, Armstrong D, Chiba $\mathrm{N}$, White RJ, Daniels $\mathrm{S}$, et al. The prevalence of clinically significant endoscopic findings in primary care patients with uninvestigated dyspepsia: the Canadian Adult Dyspepsia Empiric Treatment - Prompt Endoscopy (CADET-PE) study. Aliment Pharmacol Ther 2003;17(12):1481-91.

3. McColl KE, el-Nujumi A, Murray L, el-Omar E, Gillen D, Dickson A, et al. The Helicobacter pylori breath test: a surrogate marker for peptic ulcer disease in dyspeptic patients. Gut1997;40(3):302-06.

4. Malfertheiner P, Megraud F, O'Morain CA, Atherton J, Axon AT, Bazzoli F, et al. Management of Helicobacter pylori infection--the Maastricht IV/ Florence Consensus Report. Gut 2012;61(5):646-64.

5. Kagimu M, Winkler C, Ddumba E. Who should be screened to reduce the endoscopy workload in Mulago Hospital? East Afr Med J 1996;73(12):832-4.

6. Ogutu EO, Kang'ethe SK, Nyabola L, Nyong'o A. Endoscopic findings and prevalence of Helicobacter pylori in Kenyan patients with dyspepsia. East Afr Med J 1998;75(2):85-9.

7. Ndububa DA, Agbakwuru AE, Adebayo RA, Olasode BJ, Olaomi OO, Adeosun OA, et al. Upper gastrointestinal findings and incidence of Helicobacter pylori infection among Nigerian patients with dyspepsia. West Afr J Med 2001;20(2):140-5.

8. Missalek W, Jones F, Mmuni K, Cutinha P. Value of fibreoptic oesophago-gastro-duodenoscopy:experience with 4000 procedures at Kilimanjaro Christian Medical Centre, Moshi, Tanzania. Trop Doct 1991;21(4):165-8.

9. Ibingira CB. Management of cancer of the stomach in Mulago Hospital Kampala, Uganda. East Afr Med J 2001;78(5):233-7.

10. Baako BN, Darko R. Incidence of Helicobacter pylori infection in Ghanaian patients with dyspeptic symptoms referred for upper gastrointestinal endoscopy. West Afr J Med 1996;15(4):223-7.

11. Bashir Mohammed Tijjani ABU. Peptic ulcer disease and helicobacter pylori infection at kano,nigeria. The Internet Journal of Gastroenterology 2009 Volume 8 (Number 1).

12. Guillermo I. Perez-Perez DRaHB. Epidemiology of Helicobacter pylori Infection. HELICOBACTER 2004; Volume 9 ( Supplement 1):1-6. 